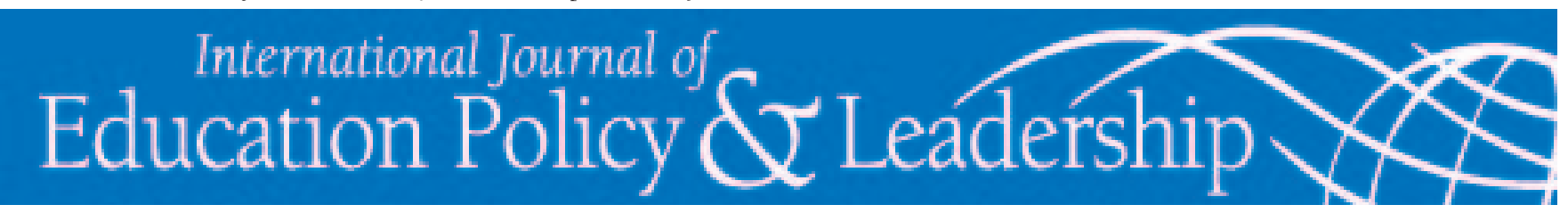

\title{
Teachers as Partners in the Prevention of Childhood Obesity
}

\author{
Mozhdeh B. Bruss, Ph.D., M.P.H., R.D. \\ Alarus Development International, LLC \\ Linda Dannison, Ph.D. \\ Western Michigan University \\ JOSEPH R. MORRIS, PH.D. ${ }^{1}$ \\ Western Michigan University \\ JACKIE QuiTUGUA, M.S. \\ CNMI Public School System \\ Rosa T. Palacios, M.P.H. \\ Hinemlo' Network \\ JUdy McGOWAN, M.A. \\ Western Michigan University \\ Timothy Michael, Ph.D. \\ Western Michigan University
}

\begin{abstract}
This paper presents a community-school-higher education partnership approach to the prevention of childhood obesity. Public elementary school personnel, primarily teachers, participated in the design and delivery of a curriculum targeting primary caregivers of 8-9-year-old children. Theoretical framework and methodological approaches guided the development of a cognitive behavioral lifestyle intervention targeting childhood obesity prevention in the Commonwealth of the Northern Mariana Islands (CNMI), a U.S. commonwealth. This project demonstrated that in populations with health disparities, teachers can be a valuable and accessible resource for identifying key health issues of concern to communities and a vital partner in the development of parent and child interventions. Teachers also benefited by gaining knowledge and skills to facilitate student and parent learning as well as impact on personal and familial health. Successful community-school-higher education partnerships require consideration of local culture and community needs and resources. Moreover, within any community-school-higher education partnership it is essential that a time-sensitive and culturally appropriate feedback loop be designed to ensure that programs are responsive to the needs and resources of all stakeholders, and that leaders and policymakers are highly engaged so they can make informed policy decisions.
\end{abstract}

Bruss, M. B. et al. (2010). Teachers as Partners in the Prevention of Childhood Obesity. International Journal of Education Policy and Leadership 5(2). Retrieved [DATE] from http://www.ijepl.org.

Childhood obesity, a risk factor for adult obesity and a predictor of cardiovascular disease in adults, is a growing global concern (Guo, Roche, Chumlea, Gardner, \& Siervogel, 1994; Drewnowski \& Popkin, 1997; Troiano, Flegal, Kuczmarski, Campbell, \& Johnson, 1995; O'Loughlin, Paradis, Meshefedjian, \& Gray-Donald, 2000; Baker, Olsen, \& Sorensen, 2007; BibbinsDomingo, Coxson, Pletcher, Lightwood, \& Goldman,
2007). Overweight children are likely to become obese adults, and the risk increases as children age (Serdula, Ivery, Coates, Freedman, Williamson, \& Byers, 1993). Additionally, parental obesity, propensity to weight gain, and environmental factors are related to childhood obesity (Whitaker, Wright, Pepe, Seidel, \& Dietz, 1997; Bouchard, 1997; Drewnowski, et al., 1997; Whitaker, Pepe, Wright, Seidel, \& Dietz, 1998).

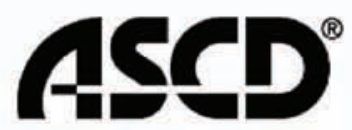

LEARN. TEACH. LEAD.
SIMON FRASER UNIVERSITY

THINKING OF THE WORLD

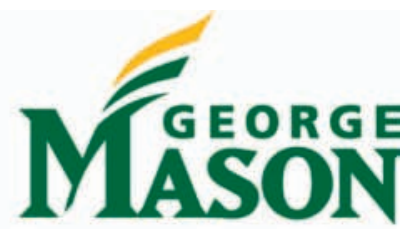


In the United States, the prevalence of childhood overweight is markedly higher among ethnic minority populations and increases with age (Ogden, Flegal, Carroll, \& Johnson, 2002). Communities around the world are beginning to monitor childhood overweight and obesity and, in some cases, design prevention strategies that include awareness, education, surveillance, advocacy, and policy. One such community is the Commonwealth of the Northern Mariana Islands (CNMI) in the Pacific region.

Cross-sectional cohort and random cluster data from the CNMI suggest that more than 30 percent of children may be at risk of overweight or overweight ( $\geq 85$ th percentile in Body Mass Index $\left[\mathrm{kg} / \mathrm{m}^{2}\right]$ for age and gender) based on the CDC reference population (CNMI Food and Nutrition Policy and Ten-Year Plan of Action, 1996; Novotny, Coleman, Tenorio, Davison, Camacho, Ramirez, Vijayadeva, Untalan, \& Tudela, 2007; School Health Profile, Youth Risk Behavior and BMI: How CNMI schools data can create a healthy environment for all students, 2008). Related to the pervasiveness of childhood obesity, is a prominent concern for the prevalence of adult obesity and the risk for type II diabetes mellitus (T2DM) among the indigenous population in the CNMI (Evaluation of Public Health Impact of PCB Contamination, Public Health Assessment, Agency for Toxic Substances and Disease Registry, US Department of Health and Human Services, 2004; Maternal and Child Health Needs Assessment Summary, Commonwealth of Northern Mariana Islands, 2005). Additionally, because body fatness in children may be associated with T2DM, cardiovascular disease, and physical inactivity, YRBS findings from the CNMI regarding physical activity and inactivity further suggested the need to carefully consider childhood obesity and associated risk factors for CNMI youth and to collaboratively develop culturally relevant interventions (Andersen, Crespo, Bartlett, Cheskin, \& Pratt, 1998; Roussos \& Fawcett, 2000; Ball \& McCargar, 2003; La Monte, Blair, \& Church, 2005; Maternal and Child Health Needs Assessment Summary, Commonwealth of Northern Mariana Islands, 2005; Youth Risk Behavior Surveillance System (YRBSS), 2008).

\section{Background}

The CNMI Food and Nutrition Council (FNC) was established in 1994 with the goal of bringing about a healthier and more physically fit CNMI community. FNC members were term-appointed by the CNMI governor. One of the objectives of the FNC was to reduce the prevalence of childhood obesity. The School-Based Nutrition and Physical Activity Partnership Program (SNAPP) was established by the FNC to develop and implement strategies to prevent childhood obesity and to promote health and wellness at all schools in the CNMI. The Childhood Obesity Prevention Research Project (COPRP) was then initiated as a community-schoolhigher education partnership project. The following five objectives guided the work of COPRP in the CNMI: (a) design and development of a scientifically sound intervention program that is family-friendly and supports psychosocial, sociocultural, and familial elements of the community; (b) design and testing of sociocultural and familial educational materials and activities for use in the prevention of childhood obesity; (c) building local capacity through the training of facilitators with knowledge and skills in childhood obesity prevention; (d) supporting the work of community agencies targeting the prevention of childhood obesity, T2DM and promoting a more sustainable community and family environment; and (e) development of a process that targets childhood obesity and can be replicated elsewhere using evaluation methods. COPRP engaged and trained public elementary school personnel, primarily teachers, as principal facilitators of education for primary caregivers of 8-9-year-old children in the CNMI.

The following phases reflect the systematic process used to achieve the COPRP objectives in the CNMI.

Phase I: Identified sociocultural and familial factors related to diet, weight normalcy, and physical activity and inactivity among primary caregivers (Bruss, Morris, \& Dannison, 2003; Bruss, Morris, Dannison, Orbe, Quitugua, \& Palacios, 2005);

Phase II: Established the need and identified strategies and barriers for delivery of a parent nutrition education program; Phase IIIA: Engaged school personnel, primarily teachers, as partners in identifying effective elements of a cognitive behavioral lifestyle intervention and developed a curricular intervention entitled Project Familia Giya Marianas (PFGM) targeting primary caregivers in the prevention of childhood obesity; and

Phase IIIB: Evaluated the implementation of PFGM targeting primary caregivers of third grade children in all public elementary schools (Bruss, Michael, Morris, Applegate, Dannison, Quitugua, Palacios, \& Klein, 2010). 
This paper mainly presents information from Phase IIIA of COPRP. It describes the theoretical framework and methodological approaches along with processes and activities involved in the development of the curricular intervention. It also discusses practice and policy implications for engaging schools and teachers in such endeavors.

\section{Theoretical Framework and Methodological Approaches}

The following theoretical framework and methodological approaches guided phase IIIA of this project, which resulted in the development of the curricular intervention: (a) Participatory Action Research, (b) curricular development model, and (c) ROPES (Review, Overview, Presentation, Exercise, and Summary) lesson plan format.

\section{Participatory Action Research}

Participatory Action Research (PAR) is an empowermentbased approach that engages individuals at the grassroots level to influence systemic change in a community by mobilizing resources to those in greatest need. PAR can be used to improve the quality of organizational systems by engaging practitioners to analyze data to improve their own practice (Bogdan \& Biklen, 1998). For the purpose of this project, five elements of PAR were used to facilitate development of the intervention: (a) engage local school personnel to identify effective systemic change; (b) support school and community members in the identification of key issues (concepts) based on assumptions and findings from the exploratory study and literature review (themes); (c) lead teams of teachers and school personnel in developing case studies and content that capture culturally relevant issues for the creation of lesson plans; (d) facilitate groups to analyze and provide feedback for lesson plan presentations; and (e) partner with community members in formalizing strategies and solutions. COPRP utilized a community-based participatory research approach (CBPR), which is predicated on the five elements of PAR but includes an emphasis on an egalitarian relationship between the community, school, and higher education (Minkler, 2005).

\section{Curricular Development Model}

Figure 1 (page 4) presents the curricular development model, which is adapted from the field of human ecology and Tyler's theory of curriculum development. Human ecology assumes that all parts of the environ- ment are interrelated and influence each other (Andrews, Bubolz, \& Paolucci, 1980). On the basis of Tyler's curricular development model (Tyler, 1949), three sources of information contributed to the development of the goals:

(a) participants-teachers, school personnel, community members, and agency representatives who participated in the training;

(b) society-results of exploratory study with primary caregivers and analysis of secondary data from the community; and

(c) subject-scientific literature related to the factors and mediators of childhood obesity along with recommendations from professional organizations.

The overarching goal of the curricular intervention was to provide primary caregivers with cognitive behavioral knowledge and skills related to the prevention of childhood obesity. Process objectives focused on teachers delivering a scientifically based and culturally appropriate curriculum to primary caregivers of elementary school-age children. The expected outcomes supported promotion of a healthy BMI according to the growth chart by age and gender among elementary school children and reduction in prevalence of childhood obesity. Concepts or key ideas were identified from the three sources of information mentioned above and used as the basis for the development of the ROPES formatted lesson plans described below. Evaluation, an integral part of the curricular development model supported ongoing learning and improvement of the goal of the intervention.

\section{ROPES Lesson Plan Format}

ROPES is an acronym describing the five components of a lesson plan: Review, Overview, Presentation, Exercise, and Summary. The following describes each of these components within the context of a session delivered by facilitators to participants. During review, facilitators explore participants' background knowledge to create a transition from past learning to the concept they plan to introduce. The overview of the new concept is an opportunity to inform participants of the plan for the session, because adults may be more receptive to learning when they are familiar with plans and expectations (Knowles, 1980). The facilitator then presents the lesson or the new concept that is the heart of the session. After the presentation, participants engage in exercise activities that amplify the new concept. Participants are more likely to transfer their learning to other situations if the exercise activity is realistic. And, finally, the lesson is summarized to reinforce the learning that has occurred. This part 
Figure 1. Curricular Development Model

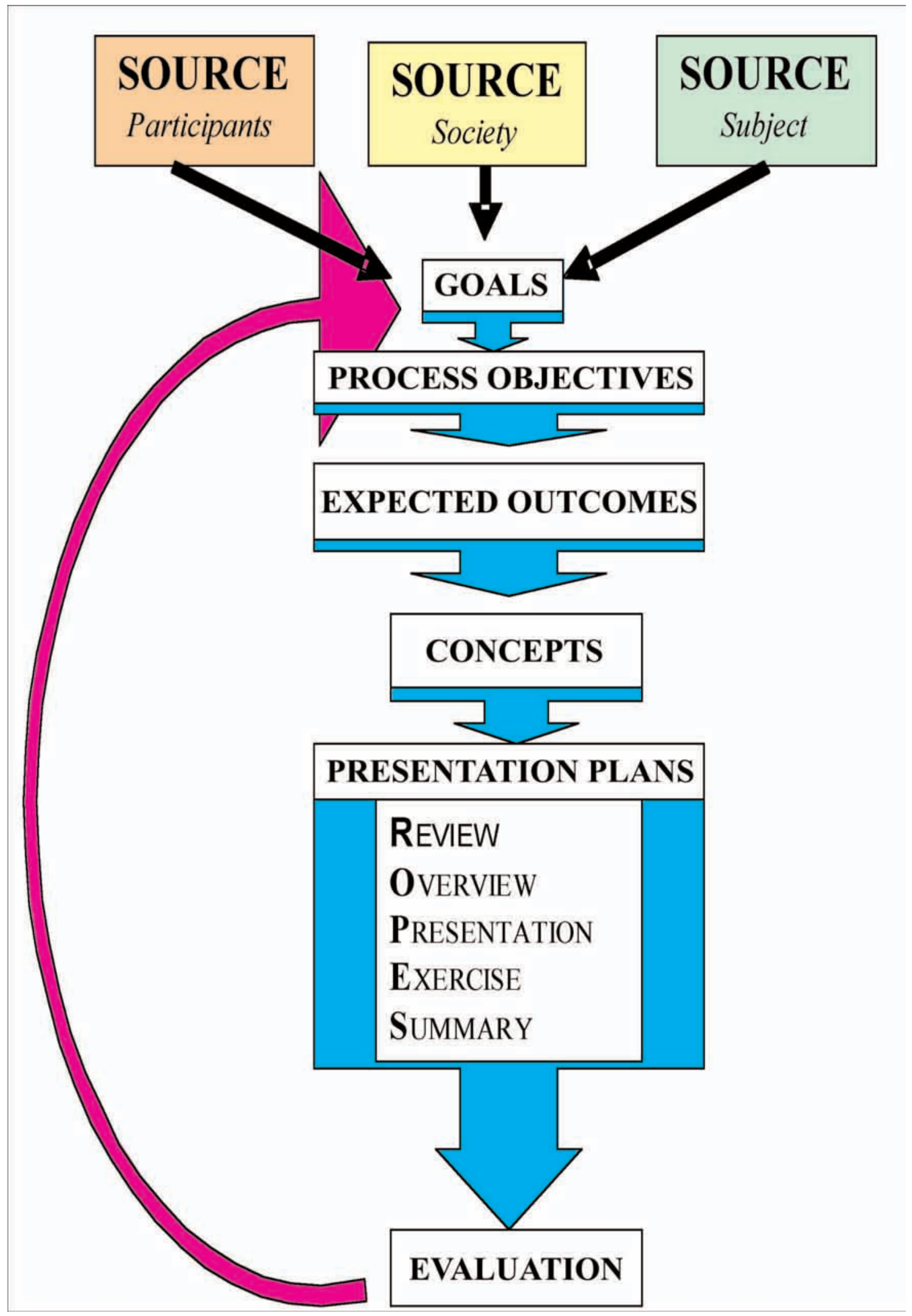


includes reflection, questioning, and/or review of information presented. The ROPES format was selected for PFGM, because it is an effective and systematic way to sequence the structure of an adult focused learning session (Glista \& Petersons, 2003) delivered by facilitators (primarily teachers) to participants (primary caregivers). Figure 2 (page 6) presents a sample ROPES lesson plan template, especially developed for this intervention.

\section{Processes}

\section{Overview of Training Workshop}

The CNMI Public School Office of Curriculum and Instruction invited participants who had demonstrated a high level of involvement in science and/or health activities to collaborate in efforts targeting the prevention of childhood obesity. A total of forty-one individuals (teachers, school personnel, and community members) participated in a training workshop. The majority (68\%) of the participants were elementary school teachers. Prior to the training workshop, a needs/strength assessment was administered to potential participants. Information obtained from this assessment, along with findings from phases I and II of COPRP and empirical studies on childhood obesity, were used to design the content and delivery of the training workshop. The content of the workshop included (a) information on childhood obesity from a public health perspective, factors related to childhood obesity, and empirically based childhood obesity intervention programs; (b) findings from the exploratory study and the literature regarding sociocultural, familial, and psychosocial mediators of childhood obesity, along with strategies for the prevention of childhood obesity; (c) information on diversity of family structures and dynamics, along with development of a family plan; (d) training in design and structure of curriculum using the ROPES lesson plan format; and (e) knowledge and skills related to facilitation of group sessions.

During the training, time was dedicated to exploring the implementation of the intervention. Small-group discussions focused on recruitment and retention of primary caregiver participants. Delivery of the intervention involved discussing details, such as where sessions for primary caregivers would be held and who would deliver the sessions. School personnel, primarily teachers, would serve as key facilitators for delivering the intervention as an after school program to primary caregivers of elementary school children. Three main reasons were identified for this approach: (a) teachers are perceived as a source of knowledge by parents of elementary school children; (b) teachers are the most prevalent professional resource within a school that could potentially deliver and sustain an education-based intervention for an extended period of time; and (c) teachers have the potential to influence parents and children and thus effect systemic and sustainable change.

School personnel engaged as facilitators for delivering the intervention required capacity building in science-based content and the skills of group leadership and facilitation. The role of group facilitator with adult learners (primary caregivers) necessitated education, process and practice (Yalom, 1995; Yalom, \& Yalom, 1998).

\section{Curriculum Development Activity}

A major activity of phase IIIA was to involve teachers and other training workshop participants in the process of curriculum development to ensure cultural relevance of the intervention and to enhance capacity building (Yazzie-Mintz, 2007). Using the curricular development model, participants drew information from three sources and identified four themes for the curriculum: (a) weight normalcy, (b) diet, (c) physical activity, and (d) physical inactivity. The themes were written on a flip chart and the entire group identified at least three concepts per theme. In this process, the three sources of information (participants, society, and subject) were used to identify and prioritize concepts as the framework for the lesson plans. Following general training in ROPES, school teams were formed. Each group focused on one concept and developed a lesson plan as a small-group exercise. As part of the curriculum development activity, participants were involved in (a) developing learning objectives, (b) writing culturally appropriate case studies, (c) developing logic models for the lesson plan, (d) learning elements of instrument design, (e) formulating questions for discussion, (f) designing skill-building activities for parents and children, and (g) incorporating virtues (character-based) educational activities. Following the curriculum development activity, each group presented their lesson plan for analysis and critique by the training workshop participants and project collaborators (CNMI and higher education partners).

\section{Assessment and Evaluation}

As part of the CBPR process, participants in this four-day training workshop engaged in learning research and evaluation concepts such as logic model (theory of change), instrument development, and protection of human subjects. This important component of the train- 
Figure 2. Sample ROPES Lesson Plan Template

\section{Facilitators: \\ Participants: \\ Curriculum Title: \\ Key Concept: \\ Name of Lesson:}

CodeSystem

C 1 Content

E Exercise

D Discussion Questions

$\mathrm{H}$ Home Activity

\begin{tabular}{ll}
\hline \hline Goal & The goals of this lesson plan is to: \\
Process Objectives & The facilitators will: \\
Outcomes & Primary Caregivers will:
\end{tabular}

Handouts

Teaching Supplies

Equipment/ Technology

Food Supplies

Materials for all lesson plans

\begin{tabular}{l} 
REVIEW: (10 minutes) Where the leamer is.... Facilitator gathers input on what \\
participants know about theskill, feels about theskill, can do with the skill \\
Code $\mid$ Teaching Strategies: \\
\hline Transition:
\end{tabular}

Facilitator Reflections Notes:

OVERVIEW: (5 minutes) Where the leamer is going. . F acilitator tells and shows the learner what they are going to leam and how it links up to the lesson's task (s) and objective(s)

Facilitator shows and tells leamers why thev need to leam the skill (s).

\begin{tabular}{l|l|l|l}
\hline Code & Teaching Strategies: & Slide(s) & Outcomes
\end{tabular}

Transition:

Facilitator Reflections Notes:

PRESENTATI ON (45 minutes) How the leamer will get there. . Facilitator shows the skill, and tells each step of the skill; participants do each step of the skill.

\begin{tabular}{l|l|l|l} 
Code & Teaching Strategies: & Slide(s) & Outcomes
\end{tabular}

Transition:

Facilitator Reflections Notes:

EXER CISE (10 minutes) How to make sure the leamer gets there.... Participants repeat doing the skill and apply the use of the skill in a group setting.

\begin{tabular}{l|l|l|l} 
Code & Teaching Strategies: & Slide(s) & Outcomes
\end{tabular}

Transition:

Facilitator Reflections Notes:

SUMMA RY: (5 minutes) Checking to seeif the leamer got there.... Facilitator checks to see if participants mastered the skill/concept?

\begin{tabular}{l|l|l|l} 
Code & Teaching Strategies: & Slide(s) & Outcomes \\
\hline & & &
\end{tabular}

Transition:

Facilitator Reflection Notes: 
ing was needed to further support the community and school as partners in this endeavor. Additionally, participants identified and discussed risk factors related to childhood obesity and effective health promotion strategies in the CNMI. A set of different assessments and exercises were used with participants to enhance the relevance and application of the training: (a) a family assignment sheet designed to identify key issues, challenges, and strengths affecting family dynamics with implications for childhood obesity; (b) a family plan application exercise using a culturally relevant case study; (c) a psychosocial skills assessment based on a related case study; (d) a questionnaire designed to identify psychosocial factors related to childhood obesity; and (e) a questionnaire designed to assess competency in group leadership and facilitation skills. The technical nature of these materials was monitored during the training workshop with consideration for effectively tailoring them to the needs of the participants. Participants also contributed to the development of a program logic model which guided the evaluation of activities and part- nerships on the basis of the objectives of the project and expected outcomes (Chaffee, 1994; Veney \& Kaluzny, 1998; Lawson, Claiborne, Hardiman, Austin, \& Surko, 2007). Figure 3 presents the logic model specific to the training workshop that ultimately resulted in the development of a curriculum for the prevention of childhood obesity targeting primary caregivers of young children. Activities, processes, and outcomes were monitored with relevant quantitative and qualitative data sources.

During the third phase of the project (development and implementation of the intervention) both formative and summative evaluation questions were identified and investigated. The following three questions guided the formative evaluation of the project during the development of the intervention, which consisted mainly in the evaluation of the training workshop: (a) what is the quality of the content and delivery of the training and the lesson plans?; (b) what barriers/obstacles interfere with developing the lesson plans and the intervention?; and (c) what revisions in materials/content and additional technical support is needed to develop the intervention?

Figure 3. Program Logic Model for Training Workshop

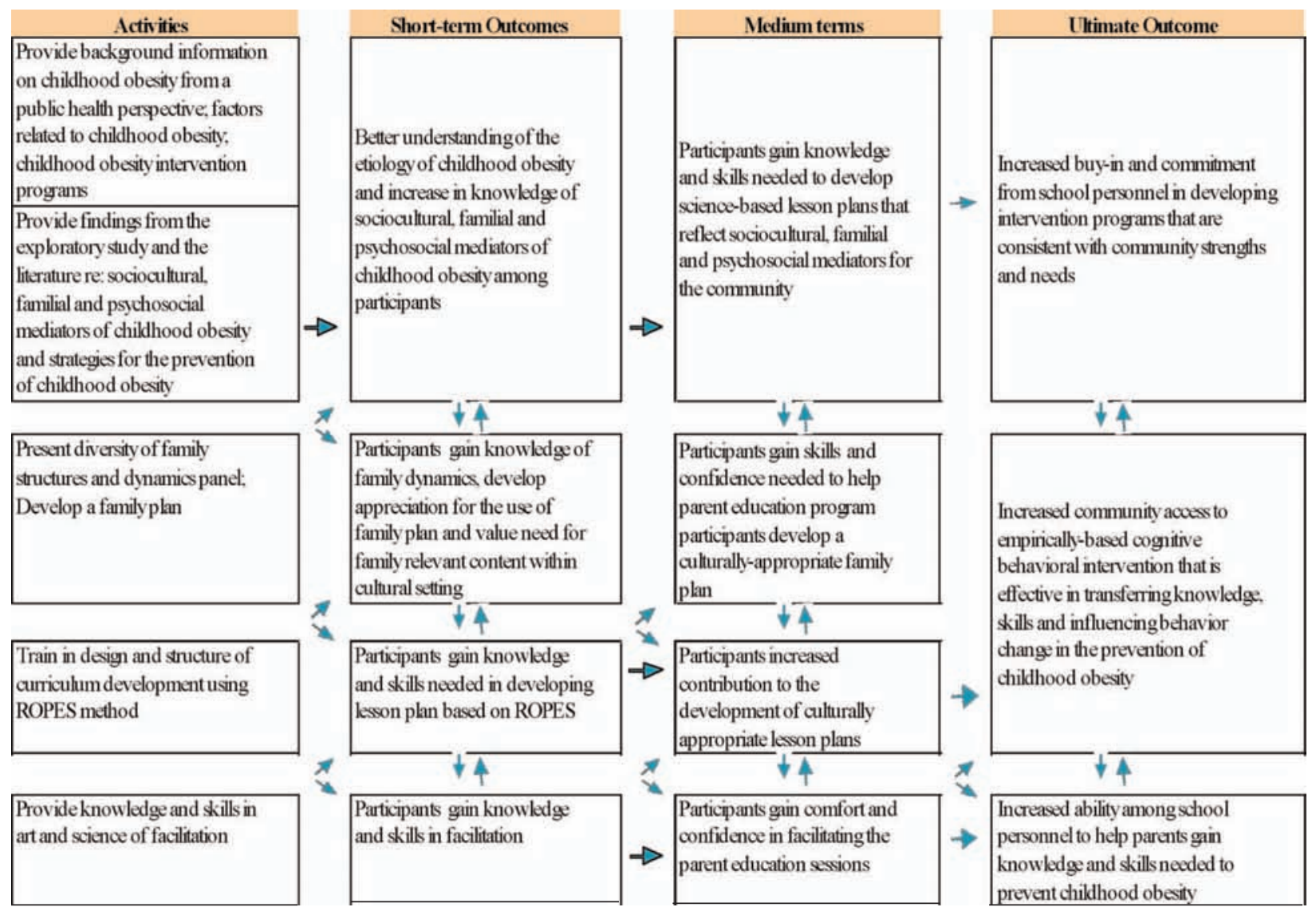


Participants in the training workshop used a variety of evaluation instruments to provide feedback. One such instrument invited responses to retrospective pre/post questions that described learning related to specific outcomes (Mays, \& Pope, 1995). While the retrospective pre/post design has some limitations that may impact results such as memory related recall issues and recall accuracy, the pre/post questions formulated for this training were developed to aid the recall process by asking about specific events/behaviors and gave participants a time frame to refer to, i.e., "BEFORE you began this training" (Rockwell, \& Kohn, 1989; Pratt, McGuigan, \& Katzev, 2000; Davis, 2003). Participants were also invited to provide feedback on each session and the overall workshop (materials, workshop format, presenters, and overall usefulness). This information was aggregated and participants were not distinguished by demographic identifiers such as profession, due to the limitation in cell size. The "Evaluate the Lesson Plan" worksheet was used to critique the group lesson plan presentation for cultural relevance. Additionally, project collaborators provided feedback and exchanges on the following: (a) content of the lesson plans reflecting knowledge of childhood obesity and factors related to it; (b) structure of lesson plans to ensure that all the components were included; and (c) delivery of the lesson plans with consideration for the target population (CNMI primary caregivers).

Other assessment and formative evaluation activities were conducted after the training workshop and continued through the development and implementation of the intervention. These included (a) content and context experts' review of the lesson plans for accuracy and relevance of information, (b) measure of the different components of the lesson plan and their influence on facilitating behavior change, (c) review of primary caregiver participants' family plans for content, (d) facilitators' feedback regarding development of the family plans by primary caregiver participants, (e) primary caregiver participants' feedback regarding development of family plans, (f) primary caregiver participants' attendance and retention, and (g) facilitators' and primary caregiver participants' feedback regarding quality of content and delivery of the lesson plans.

During phase IIIB, summative evaluation questions included (a) outcome of training efforts, (b) the need for training of school personnel in the prevention of childhood obesity, (c) replication of training in the prevention of childhood obesity with other school personnel and community members, and (d) outcome of the intervention on the primary measure (child's BMI) and other related variables such as diet, physical activity/inactivity, self esteem, and parent-child interaction.

\section{Development of Cognitive Behavioral Lifestyle Intervention Curriculum}

During the training workshop, participants identified a set of twelve concepts as the basis for the development of the curriculum. Participants received ROPES training to assist with the development of lesson plans. Based on the twelve concepts, small groups were formed. Each group drafted and presented a lesson plan (at different stages of development) to the workshop participants and project collaborators. Workshop participants reported their appreciation for learning new skills and knowledge related to ROPES, which they would use in the classroom and with other educational activities. Participants also found ROPES structure helpful in learning nutrition information, which supported its use in the development of the lesson plans (Capacity Building in the Prevention of Childhood Obesity, COPRP Report, 2007).

Following the training workshop, draft lesson plans were reviewed and rated for content and consistency with ROPES structure by two independent reviewers. Their analysis indicated a need for further development and revision including combining similar concepts prior to using the lesson plans with primary caregivers. Over a period of three months, extensive work by a multidisciplinary team further developed the curricular intervention. A set of eight lesson plans emerged as the basis of the cognitive behavioral lifestyle intervention curriculum for the prevention of childhood obesity. The lesson plans were developed based upon (a) information from workshop participants, (b) academic literature sources, (c) recommendations from professional organizations such as the American Academy of Pediatrics and the American Dietetic Association, (d) reports from U.S. government agencies and the World Health Organization, and (e) review and input from local CNMI collaborators and content area academicians from disciplines related to childhood obesity. Lesson plans were formatted to ROPES structure and improved to include (a) essential guiding questions; (b) goals based on scientific literature; (c) process objectives delineating the role of the facilitator; (d) a logic model identifying immediate, intermediate, and long-term outcomes; (e) expected outcomes for primary caregivers and children; (f) teaching strategies with outcomes; (g) visual slides of the lesson; (h) a glossary; (i) references; (j) related handouts; and (k) assessment and evaluation questionnaire forms. 
This eight lesson curricular intervention was designed to create and support a childhood obesity prevention environment. The lessons focused on four key elements: (a) physiological and sociocultural elements: [lesson 1 - energy balance and weight normalcy]; (b) psychosocial elements: [lesson 4 - preserving self esteem] and [lesson 8 - motivation to support and sustain healthy behavior]; (c) dietary elements: [lesson 5 - label reading], [lesson 6 - food portions], and [lesson 7 - healthy eating environment]; and (d) activity and inactivity elements: [lesson 3 - promoting time for family activities] and [lesson 2 - physical inactivity]. The number of a lesson indicates the order in which the lesson was presented to the primary caregivers during the implementation of the intervention. The sequence of the lessons was guided by the nature of the lesson content as it related to the cultural context of the CNMI.

\section{Summary of Activities}

During phase I of the project, sociocultural and familial factors related to diet, weight normalcy, and physical activity and inactivity among primary caregivers were identified. Phase II established the need and identified strategies and barriers for delivery of a parent nutrition education program. Phase IIIA primarily engaged teachers as partners in identifying effective elements of a cognitive behavioral lifestyle intervention targeting primary caregivers of elementary school children. Phase IIIB involved evaluation of the implementation of PFGM. Each phase lasted approximately one year, except for phase IIIB, which lasted for two years. During all phases, local CNMI collaborators were integral to maintaining the cultural integrity and relevance of the activities related to this project. In addition, ongoing discussions with CNMI leaders and policy makers regarding the project were conducted.

In an effort to consolidate and incorporate the lessons learned from COPRP in future endeavors, CNMI community members from different sectors (health, education, business, and government leadership) met with a broad-based higher education group (exercise science, food and nutrition, early childhood education, physical education, psychology, parent and adult education, pediatric endocrinology, epidemiology, and research and evaluation methodology). Over several days, the participants reviewed and discussed directions, needs and resources required in sustaining current efforts and other relevant strategies. As a follow-up, a community-based multi-sector group in the CNMI is seeking to sustain and expand efforts related to the prevention of childhood obesity in collaboration with the community.

\section{Implications for Practice}

Community-school-higher education partnerships that engage teachers in design and delivery of interventions to primary caregivers in the prevention of childhood obesity demonstrate the development of a successful collaboration (Lawson, et al., 2007). Teachers are highly regarded community members, who have the trust of the community and are valued by the parents of their students. Our project found that a number of benefits can arise from this kind of engagement. Involving teachers in the design and development of curricular material provides a practical and culturally appropriate approach to identifying key issues in a community (Riel, 1998; YazzieMintz, 2007). Additionally, innovative solutions to challenging problems can emerge when teachers are invited to reflect on the needs of their students by interacting with primary caregivers. Teachers may also benefit from participation in such partnerships. In this project, an ecological perspective helped teachers gain knowledge and skills related to childhood obesity prevention, which can influence them personally as well as their families, their students, and their students' families.

This project highlighted the importance of a multidisciplinary approach to the presentation of materials related to the prevention of childhood obesity. Successful community-school-higher education partnerships require consideration of local culture and community needs and resources. Furthermore, lessons learned from such partnerships can provide insight and direction into how we might use a theoretical framework and methodological approaches such as PAR, the curricular development model, and ROPES to design interventions targeting other public health issues, such as adult obesity, chronic diseases, and mental health concerns.

\section{Policy and Leadership Implications}

In light of the growing concern in childhood obesity and the need for different sectors of society to participate in solutions that can address this concern, this communityschool-higher education partnership highlights the important role that teachers and schools can play in this effort. Similarly, other communities in partnership with schools have utilized different strategies such as surveillance, educational interventions, advocacy, and policy (Justus, Ryan, Rockenbach, Katterapalli, \& CardHiginson, 2007). As communities become increasingly 
focused on addressing this and other public health issues, schools' access to children and their families becomes an important area of focus. In this process, school leaders and policymakers may need to monitor and investigate both the intended and the unintended outcomes of suggested strategies, interventions, and allocation of resources. Early engagement of school and community leaders and policymakers as partners in this dialogue can focus the discussion on strategies, policies, resources, competing priorities, and additional funding support (Rubin, 2002). Indeed, as public schools become more actively involved in this and other community-wide public health issues, policymakers and other community leaders are attempting to secure funding to sustain and support the role of schools in such efforts (Sixteenth Northern Marianas Commonwealth Legislature Session, H.B. No. 16-102, 2008).

\section{Conclusion}

This paper described processes utilized by a communityschool-higher education partnerships to develop culturally relevant interventions that target public health concerns. Such initiatives have the potential to be more effective and sustainable when they build on partnerships that reflect interest in the community at large. In designing community-based interventions it is necessary to consider the scientific content and to identify delivery methods that are suitable to the population; this project's use of the curricular development model, ROPES, PAR, and assessment and evaluation supported the development of an intervention that is culturally appropriate and scientifically sound. The success of community-schoolhigher education engagement in the development of such interventions requires careful attention to a welldesigned feedback loop (formative planning, training, evaluation, and reporting) that is time-sensitive, culturally appropriate, and responsive to the needs and resources of all stakeholders. In this process, leaders and policymakers are also engaged in order to facilitate informed policy decisions with regard to outcomes and resources.

\section{References}

Andersen, R. E., Crespo, C. J., Bartlett, S. J., Cheskin, L. J., \& Pratt, M. (1998). Relationship of physical activity and television watching with body weight and level of fatness among children. Journal of American Medical Association, 279, 938-942.

Andrews, M. P., Bubolz, M. M., \& Paolucci, B. (1980). An ecological approach to study of the family. Marriage \& Family Review, 3, 29-49.
Baker, J. L., Olsen, L. W., \& Sorensen, T. I. A. (2007). Childhood Body-Mass Index and the risk of coronary heart disease in adulthood. New England Journal of Medicine, 357(23), 2329-2337.

Bibbins-Domingo, K., Coxson, P., Pletcher, M. J., Lightwood, J., \& Goldman, L. (2007). Adolescent overweight and future adult coronary heart disease. New England Journal of Medicine, 357(23), 2371-2379.

Ball, G. D. C., \& McCargar, L. J. (2003). Childhood obesity in Canada: A review of prevalence estimates and risk factors for cardiovascular diseases and type 2 diabetes. Canadian Journal of Applied Physiology, 28, 117-140.

Bogdan, R. C., \& Biklen, S. K. (1998). Qualitative research for education: An introduction to theory and methods. Boston: Allyn and Bacon.

Bouchard, C. (1997). Obesity in adulthood: The importance of childhood and parental obesity. New England Journal of Medicine, 337, 926-927.

Bruss, M. B., Michael, T.J., Morris, J.R., Applegate, B., Dannison, L., Quitugua, J.A., Palacios, R.T., \& Klein, D.J. Childhood obesity prevention: An intervention targeting primary caregivers of school children. Obesity Research, 18(1), 99-107..

Bruss, M., Morris, J., \& Dannison, L. (2003). Prevention of childhood obesity: Sociocultural and familial factors. Journal of American Dietetic Association, 103(8), 1042-1045.

Bruss, M. B., Morris, J. R., Dannison, L., Orbe, M. P., Quitugua, J. A., \& Palacios, R. T. (2005). Food, culture, and family: Exploring the coordinated management of meaning regarding childhood obesity. Health Communication, 18(2), 155-175.

Capacity Building in the Prevention of Childhood Obesity, COPRP Report (2007). Prepared by Project Collaborators. Western Michigan University.

Chaffee, J. (1994). Thinking critically (4th ed.). Boston: Houghton Mifflin.

CNMI National Food and Nutrition Policy and TenYear Plan of Action (1996). CNMI National Food and Nutrition Advisory Council, Saipan, MP. Out of Print.

Davis, G. A. (2003). Using a Retrospective Pre-Post Questionnaire to Determine Program Impact. Journal of Extension, 41(4), Available at: http://www.joe.org/joe/2003august/tt4.php. 
Drewnowski, A., \& Popkin, B. M. (1997). The nutrition transition: New trends in the global diet. Nutrition Reviews, 55(2), 31-43.

Evaluation of Public Health Impact of PCB Contamination, Public Health Assessment, Agency for Toxic Substances and Disease Registry, US Department of Health and Human Services. (August 31, 2004). Retrieved December 29, 2007, from http://www.atsdr.cdc.gov/HAC/pha/saipan083104CM/saipan083104-CM-p3.html.

Glista, S., \& Petersons, M. (2003). A model curriculum for interdisciplinary allied health gerontology education. Gerontology \& Geriatrics Education, 23(4), 27-40.

Guo, S. S., Roche, A. F., Chumlea, W. C., Gardner, J. D., $\&$ Siervogel, R. M. (1994). The predictive value of childhood Body Mass Index values for overweight at age 35 y. American Journal of Clinical Nutrition, 59, 810-819.

Justus, M. B., Ryan, K. W., Rockenbach, J., Katterapalli, C., \& Card-Higginson, P. (2007). Lessons learned while implementing a legislated school policy: Body Mass Index assessments among Arkansas's public school students. Journal of School Health, 77(10), 706-13.

Knowles, M. S. (1980) The modern practice of adult education: Andragogy versus pedagogy, Englewood Cliffs: Prentice Hall/Cambridge.

Lawson, H. A., Claiborne, N., Hardiman, E., Austin, S., \& Surko, M. (2007). Deriving theories of change from successful community development partnerships for youths: Implications for school improvement. American Journal of Education, 114, 1-40.

LaMonte, M. J., Blair, S. N., \& Church, T. S. (2005). Physical activity and diabetes prevention. Journal of Applied Physiology, 99, 1205-1213.

Maternal and child health needs assessment summary, Commonwealth of Northern Mariana Islands. (July, 2005). Retrieved December 29, 2007, from https://perfdata.hrsa.gov/mchb/mchreports/documents/NeedsAssessments/2006/MPNeedsAssessment.pdf.

Mays, N., \& Pope, C. (1995). Qualitative Research: Observational methods in health care settings. British Medical Journal, 311, 182-4.

Minkler M. (2005). Community-based research partnerships: challenges and opportunities. Journal of Urban Health, 82(2 Suppl 2), ii3-iil2.
Novotny, R., Coleman, P., Tenorio, L., Davison, N., Camacho, T., Ramirez, V., Vijayadeva, V., Untalan, P., \& Tudela, M.D. (2007). Breastfeeding is associated with lower Body Mass Index among children of the Commonwealth of the Northern Mariana Islands. Journal of American Dietetic Association, 107(10), 1743-1746.

Ogden, C. L., Flegal, K. M., Carroll, M. D., \& Johnson, C. L. (2002). Prevalence and trends in overweight among U.S. children and adolescents, 1999-2000. Journal of American Medical Association, 288, 1728-1732.

O'Loughlin, J. O., Paradis, G., Meshefedjian, G., \& Gray-Donald, K. (2000). A five-year trend of increasing obesity among elementary schoolchildren in multiethnic, low-income, inner city neighborhoods in Montreal, Canada. International Journal of Obesity, 24, 1176-1182.

Pratt, C.C., McGuigan, W.M., Katzev, A.R. (2000). Measuring program outcomes: Using retrospective pretest methodology. American Journal of Evaluation. 21(3), 341-349.

Riel, M. (1998). Teaching and learning in the educational communities of the future. In C. Dede (Ed.), Learning with Technology (1998 ASCD Yearbook). Alexandria, VA: Association for Supervision and Curriculum Development, pp. 171-198.

Rockwell, S. \& Kohn, H. (1989). Post-then-pre evaluation. Journal of Extension, 27 (2), Available at: http://www.joe.org/joe/1989summer/a5.php.

Roussos, S. T., \& Fawcett, S. (2000). A review of collaborative partnerships as a strategy for improving community health. Annual Review of Public Health, 21, 369-402.

Rubin, H. (2002). Collaborative leadership: Developing effective partnerships in communities and schools. Thousand Oaks, CA: Corwin.

School Health Profile, Youth Risk Behavior and BMI: How CNMI schools data can create a healthy environment for all students (September, 2008).

Provided by Office of Curriculum and Instructions $\&$ Assessment in collaboration with all our CNMI Public School Leaders and Learning Community. Saipan, MP: Elite Printing.

Serdula, M. K., Ivery, D., Coates, R. J., Freedman, D. S., Williamson, D. F., \& Byers, T. (1993). Do obese children become obese adults? A review of the literature. Preventive Medicine, 22, 167-177. 
Sixteenth Northern Marianas Commonwealth Legislature Session, 2008 H.B. No. 16-102. Northern Marianas Commonwealth Legislature. (May 15, 2008). Retrieved Retrieved February 12, 2010, from http://www.cnmileg.gov.mp/documents/house/hse_ bills/16/HB16-102.pdf.

Troiano, R. P., Flegal, K. M., Kuczmarski, R. J., Campbell, S. M., \& Johnson, C. L. (1995). Overweight prevalence and trends for children and adolescents (National Health and Nutrition Examination Surveys, 1963 to 1991). Archives of Pediatrics and Adolescent Medicine, 149(10), 1085-1091.

Tyler, R. W. (1949). Basic principles of curriculum and instruction. Chicago: University of Chicago Press.

Veney, J., \& Kaluzny, A. (1998). Evaluation and decision making for health services. Chicago: Health Administration Press.

Whitaker, R. C., Wright, J. A., Pepe, M. S., Seidel, K. D., \& Dietz, W. H. (1997). Predicting obesity in young adulthood from childhood and parental obesity. New England Journal of Medicine, 337, 869-873.

Whitaker, R. C., Pepe, M. S., Wright, J. A., Seidel, K. D., \& Dietz, W. H. (1998). Early adiposity rebound and the risk of adult obesity. Pediatrics, 101(3), 1-6.

Yalom, I. D. (1995). The theory and practice of group psychotherapy (4th ed.). New York: Basic Books.

Yalom, I. D., \& Yalom, B. (1998). The Yalom reader: Selections from the work of a master therapist and storyteller. New York: Basic Books.

Yazzie-Mintz, T. (2007). From a place deep inside: Culturally appropriate curriculum as the embodiment of Navajo-ness in classroom pedagogy [Special issue]. Journal of American Indian Education, 46(3), 72-93.

Youth Risk Behavior Surveillance System (YRBSS). National Center for Chronic Disease Prevention and Health Promotion, Centers for Disease Control (CDC). (May 9, 2008). Retrieved December 2, 2008, from http://apps.nccd.cdc.gov/yrbss/QuestYearTable.asp? ByVar=CI\&cat $=6 \&$ quest $=Q 81 \& l o c=M P \& y e a r=$ Tren d.

\section{Acknowledgments}

The authors wish to acknowledge the CNMI Public School System, the CNMI Department of Public Health, CNMI Food and Nutrition Council, CNMI Coalition for the Prevention of Childhood Obesity, Project Familia Giya Marianas facilitators, primary caregivers and their children, Mrs. Frances T. Demapan, and other community members for continued promotion of health among children and families in the CNMI. Additionally, the authors acknowledge the generous support of Larry L. Hillblom Foundation, CNMI Public School System, and Western Michigan University.

\section{Notes}

1. Corresponding author. See the IJEPL Web site (www.ijepl.org) for contact information.

IJEPL is a joint publication of the Association for Supervision and Curriculum Development, the Faculty of Education at Simon Fraser University, and the College of Education and Human Development at George Mason University. By virtue of their appearance in this open access journal, articles are free to use, with proper attribution, in educational and other non-commercial settings 90 days after initial publication. Copyright for articles published in IJEPL is retained by the authors. More information is available on the IJEPL Web site: http://www.ijepl.org 